\title{
O mestrado como via de formação de professores da educação básica para a pesquisa
}

The master's degree as a way of training teachers of basic education for research

La maestría como vía de formación de profesores de educación básica para la investigación

Menga Lüdke, doutora em Sociologia pela Universidade de Paris $X$, pós-doutora pela Universidade da Califórnia (Berkeley) e pelo Instituto de Educação da Universidade de Londres e professora titular da Pontifícia Universidade Católica do Rio de Janeiro (PUCRio) e da Universidade Católica de Petrópolis (UCP). Endereço: Atlântica, 3.514, ap. 101. CEP: 22070-001 - Rio de Janeiro, RJ. Telefone: (21) 2247-4361. E-mail: menga@puc-rio.br.

Priscila Andrade Magalhães Rodrigues, doutoranda em Educação pela PUC-Rio e professora do Colégio Brigadeiro Newton Braga (CBNB) e do curso de Pedagogia da Faculdade Batista do Rio de Janeiro (Fabat). Telefone: (21) 2481-8206. E-mail: priscilaapri@ gmail.com.

Vanessa Cristina Máximo Portella, doutoranda em Educação pela PUC-Rio e professora do Colégio Pedro II. Telefone: (21) 2436-2193. E-mail: vanessa.maximo@ig.com.br.

\section{Resumo}

O estudo se baseia no relato de 30 professores sobre o curso de mestrado que concluíram recentemente como via de preparação para a pesquisa. As conclusões confirmam a importância do curso e apontam para a discussão de vários de seus aspectos: o sistema de seleção dos candidatos, o conjunto de disciplinas e atividades oferecidas, a participação em grupos de pesquisa, o estímulo à produção discente, o processo de orientação e defesa da dissertação e todo o conjunto 
de recursos oferecidos pela instituição universitária na qual se situa o programa de pós-graduação. O conjunto de entrevistados reconheceu a influência da experiência vivida no mestrado sobre sua concepção de pesquisa, seu potencial e suas limitações.

Palavras-chave: Mestrado. Pesquisa. Professor da Educação Básica.

\section{Abstract}

The study is based on information provided by 30 teachers about a Masters Program that they had recently concluded in order to prepare to engage in the practice of research. The findings confirm the importance of the program and provide a basis for discussing several of its aspects: the system for selecting candidates, the set of disciplines and activities offered, participation in research groups, the advising process and manner of judging the dissertation, and the combination of resources offered by the university in which the graduate program is situated. The respondents recognized the influence of the Master's experience on their conception of research and on their understanding of its potential and limitations.

Keywords: Masters Course. Research. Teachers.

\section{Resumen}

El estudio se basa en el relato de 30 profesores sobre el máster que habían concluido recientemente como un medio de preparación para la investigación. Las conclusiones confirman la importancia del curso y conducen a la discusión de varios de sus aspectos: el sistema de selección de los candidatos, el conjunto de asignaturas y actividades ofrecidas, la participación en grupos de investigación, el fomento a la producción del alumnado, el proceso de orientación y defensa de la disertación y todo el conjunto de recursos oferecidos por la institución universitaria en la cual se desarrolla el programa de posgrado. El conjunto de los entrevistados reconoció la influencia de la experiencia vivida durante el máster en la concepción de su investigación, su potencial y sus limitaciones.

Palabras clave: Máster. Investigación. Profesor de Educación Básica. 


\section{Apresentação do estudo}

O curso de mestrado em Educação no Brasil tem se consolidado, ao longo dos seus quase 50 anos de existência e quase 100 programas implementados, como uma instância do ensino superior orientada para o desenvolvimento de profissionais voltados para o magistério. Como esse curso tem desempenhado sua função como preparador para a realização de atividades de pesquisa, aspecto essencial no desenvolvimento de todo profissional, de modo especial o professor? É o que buscamos investigar, em estudo que focaliza o conjunto de componentes próprios desses cursos, dentro de uma acepção ampla de currículo, a partir da perspectiva de professores da educação básica diplomados por um deles em anos recentes. Embora o mestrado venha se consolidando ao longo desses 50 anos, foi no Plano Nacional de Pós-Graduação (PNPG) 2005-2010 que os professores da educação básica passaram a ser contemplados explicitamente na formulação das políticas educacionais relativas a esse nivel de ensino.

A pesquisa se inscreve em um programa de estudos sobre o desenvolvimento profissional do professor da educação básica, iniciado em meados dos anos 1990, focalizando a questão da socialização profissional de docentes (LÜDKE, 1996). O prosseguimento desse estudo inicial, feito com professores situados ao longo das diferentes fases do ciclo de vida profissional docente (HUBERMAN, 1992), levounos a investigar, em uma segunda etapa, o papel do estabelecimento de ensino no desenvolvimento profissional de seus professores; e, finalmente, em uma terceira etapa, a visão dos formadores desses professores nos cursos de licenciatura e nos da antiga escola normal, no que se refere à formação do profissional da educação. Observamos, então, com certa decepção, que nossos entrevistados, em ambas as agências formadoras, não apontaram a formação para a pesquisa como integrante fundamental na preparação do profissional para o magistério. Intrigou-nos de tal modo essa constatação que resolvemos propor uma nova investigação, desta vez específica, sobre o papel da pesquisa na formação e na atuação do professor da educação básica. A essa altura, em 1998, já havíamos conseguido reunir um conjunto de análises e reflexões sobre o tema da profissão docente, expressas em trabalhos de teses e dissertações e nos relatórios das três etapas do estudo. 
O novo tema de estudo, as relações entre o professor e a pesquisa, também se desenvolveu em três etapas. Na primeira, procuramos verificar a prática de pesquisa e a preparação para ela, junto a professores de escolas públicas do ensino médio do Rio de Janeiro. Focalizamos estabelecimentos com certas condições favoráveis a essa atividade, tais como horas especiais e estímulos financeiros. Queríamos assegurar a possibilidade de constatar a presença da pesquisa no dia a dia da escola, ainda que de forma reduzida. Estávamos certos de que as muitas dificuldades que cercam o trabalho do professor, sobretudo nas escolas da rede pública, tornariam bastante improvável a presença da prática de pesquisa na maior parte delas. Improvável, mas não impossível. De fato, conseguimos encontrar nas quatro escolas que compuseram nossa amostra (intencional, por certo) professores que desenvolviam atividades de pesquisa. Com eles, pudemos aprofundar nosso conhecimento sobre sua concepção de pesquisa, a preparação que receberam para praticá-la nos cursos de graduação (ou lastimam não terem recebido), os tipos de pesquisa que desenvolvem ou gostariam de desenvolver e as muitas dificuldades que se interpõem entre eles e a realização de pesquisa em suas escolas. As principais constatações e análises dessa etapa do estudo vêm sendo divulgadas em artigos e capítulos de livros (LÜDKE, 2001a; 2001b; 2004).

Em uma segunda etapa desse estudo, os protagonistas foram os formadores de professores dos cursos de licenciatura de matérias centrais do currículo do ensino fundamental: matemática, português, geografia, história, ciências, educação física e ainda as chamadas disciplinas pedagógicas. Procuramos saber junto a eles, em duas universidades públicas do Rio de Janeiro, como viam a importância da formação do professor da educação básica para a pesquisa e como avaliam que ela está sendo cuidada nos cursos que lecionam. Também pedimos sua opinião sobre as possibilidades de exercício da pesquisa por parte do professor na escola de educação básica. Em geral, obtivemos uma visão positiva sobre a importância da pesquisa e de sua prática, mas uma visão bastante cética sobre sua viabilidade nas escolas (LÜDKE, 2002).

Tanto na primeira quanto na segunda etapa do estudo, nos defrontamos com o desafio de encontrar um conceito de pesquisa 
suficientemente consensual para contemplar a multiplicidade de acepções apresentadas pelos nossos informantes. Se, por um lado, o conceito acadêmico de pesquisa como construção de conhecimento de maneira rigorosa, com discussão teórica e divulgação à crítica, sempre aparecia quando pedíamos alguma definição, por outro, havia paralelamente a sugestão de outras acepções de pesquisa, algumas bastante livres, por vezes com a justificação espontânea do informante para a sua opção: "eu sei que a definição da 'verdadeira' pesquisa é essa (a acadêmica), mas não é dela que precisamos aqui na escola". Encontramos eco para essa pendência em uma literatura bastante instigante, vinda especialmente do chamado movimento da pesquisa do professor, com mais de 15 anos de militância crescente nos Estados Unidos (COCHRAN-SMITH; LYTLE, 1999; ANDERSON; HERR, 1999). Esse movimento advoga o reconhecimento e a valorização da pesquisa feita pelo professor a partir de critérios mais amplos e flexíveis, que levem em conta as características próprias de seu trabalho nas escolas e suas especificidades, sem abrir mão, entretanto, do rigor que deve caracterizar toda forma de pesquisa.

Alinhando-nos com esse movimento, propusemos uma terceira etapa para o estudo, de modo explícito, desde o seu título, "O que conta como pesquisa?", em função da procura de critérios que de fato distinguem pesquisas merecedoras desse nome de outras que a ele não fazem jus, aos olhos de quem decide se um trabalho de pesquisa merece financiamento, deve ser publicado ou pode ser apresentado em um encontro científico. A partir de uma busca prolongada, junto a organizações que acolhem contribuições de professores da educação básica, conseguimos selecionar alguns trabalhos "de pesquisa” feitos por esses professores e os encaminhamos a pesquisadores experimentados, com longa prática de avaliação de trabalhos desse tipo para agências financiadoras. Pedimos a eles que nos dissessem, com toda a liberdade, se os consideravam ou não como de pesquisa e quais as razões de sua decisão sobre cada um deles. Procuramos compor, com suas informações, uma introdução ao que nos atrevemos denominar "cultura de pesquisa”, dominante na área de educação em nosso País.

O trabalho junto aos "juízes” constituiu para nós uma consulta à Academia, à Universidade, por meio de representantes especialmente 
qualificados sobre como está sendo vista e considerada a questão da pesquisa feita pelo professor da educação básica. O termo "informantes privilegiados" parece se enquadrar muito bem nesse caso, pois, pela sua qualificação e atuação como professores e pela pesquisa que vêm desenvolvendo, eles se situam em uma perspectiva privilegiada para visualizar criticamente nosso problema em estudo e nos fornecer pistas para enriquecer essa discussão. Não desconhecemos o lado polêmico da discussão. Sabemos bem que há fortes argumentos apresentados a favor de uma clara separação entre o papel do professor e o do pesquisador, entre a tarefa de ensinar e a de pesquisar, e reconhecemos que é necessário atentar com cuidado para as respectivas exigências dessas tarefas, para não comprometer o bom cumprimento de ambas, como nos alertam Hammersley (1993) e Santos (2001). Não podemos ingenuamente pensar que a simples percepção e o reconhecimento da importância da pesquisa para o trabalho e a formação daquele professor sejam suficientes para oferecer soluções ao problema. Pela nossa investigação, rapidamente relatada, constatamos com clareza as muitas dificuldades para a prática de pesquisa por parte dos professores em suas escolas, assim como para a própria preparação desse professor como pesquisador, nos cursos de formação oferecidos pela universidade (LÜDKE, 2009).

Introduzido formalmente entre nós pelo artigo de Tardif, Lessard e Lahaye, de 1991, o tema do saber docente tornou-se logo objeto de muito interesse, de muita discussão, marcando presença em grande parte da produção bibliográfica recente na área da educação. Sua relação com o trabalho muito conhecido de Schön (1983) é evidente, mas gostaríamos de lembrá-la para evocar uma distinção que consideramos importante pelo seu significado para o novo estudo realizado. Já tivemos oportunidade de comentar algumas repercussões do trabalho fundamental de Schön sobre a complexa relação entre o professor da educação básica e a prática da pesquisa (LÜDKE, 2001a; LÜDKE; CRUZ, 2005). Ressaltamos a grande importância da visão de Schön, mais como reconhecimento do que propriamente como revelação sobre o trabalho do (bom) profissional, mas queremos apontar dois aspectos a ela ligados, que merecem consideração pelas suas consequências sobre o próprio desenvolvimento do profissional, no nosso caso, do professor. Um deles é o risco de restringir sua atuação ao âmbito de sua própria prática, 
sua sala de aula, sua escola, sua vida, isolando-o das conexões críticas imprescindiveis com a realidade maior que o cerca no espaço e no tempo, como bem ressalta Contreras (1997). O outro aspecto, muito ligado ao nosso estudo, é a quase identificação entre reflexão e pesquisa, que pode comprometer esta atividade, no caso do professor, ao julgar suficiente o ato indispensável de refletir para satisfazer a necessidade de investigar os problemas que perturbam seu trabalho e o de seus alunos.

O reconhecimento do saber docente por parte da Academia aparece como um movimento de grandes proporções e importantes repercussões. Entre nós, já é vasta a literatura a ele dedicada, sendo, portanto, impossivel sequer circunscrever aqui seus representantes mais relevantes. Assinalamos alguns exemplos ilustrativos da importância de sua contribuição, por estarem mais próximos do desenvolvimento do nosso estudo. A obra de Tardif é um deles, não apenas por ter sido um dos introdutores do tema entre nós, mas também por ter consistentemente prosseguido em seu estudo, ao longo dos anos, desde o início da década de 1990. A tese de doutorado de Borges (2002), também publicada em livro (2004), trouxe boa contribuição para o trabalho do nosso grupo de pesquisa, o GEProf, na medida em que trabalhou junto a professores das diferentes disciplinas da educação básica, procurando com cada um deles traçar os caminhos de construção de seus saberes específicos como docentes.

\section{O estudo realizado ${ }^{1}$}

Propusemos, então, em novo estudo, focalizar um elo importante da cadeia que une professor e pesquisa, cujo estudo vimos fazendo há anos. Esse elo é representado pelo mestrado, como ficou claro no parágrafo que fecha um artigo para o Cadernos de Pesquisa n ${ }^{\circ} 125$ :

Uma possível pista de aproximação foi vislumbrada na terceira etapa de nossa pesquisa [já concluída]: a opção por trabalhos "híbridos", isto é, elaborados em conjunto por docentes da escola básica e seus professores nos cursos de mestrado. Quem sabe não descobriremos aí os alicerces de uma ponte, cuja construção deveria ter sido lançada há muito tempo, ou talvez até já tenha sido, sem que tenhamos, entretanto, tido o cuidado de explorar devidamente toda a riqueza dessa possibilidade, em favor de 
um desenvolvimento mútuo. De um lado, crescem a escola básica e seus professores, recebendo estes a complementação da formação recebida na licenciatura, e ao longo de toda a sua carreira, por certo. De outro lado, cresce a universidade, pelo contato direto com os problemas vitais da educação básica, assegurado pelos seus mestrandos-professores (LÜDKE; CRUZ, 2005, p. 105).

No que se refere à relação entre o professor e a pesquisa, estamos diante de um quadro pouco animador, revelado não apenas em nossa investigação, ou em nosso País, como é apontado em vários trabalhos (TARDIF; ZOURHLAL, 2005; CARVALHO, 2004; ANDRÉ; LÜDKE, 2004; DURAND; SAURY; VEYRUNES, 2005). A questão da pesquisa do professor da educação básica, ou do professor pesquisador, além das dificuldades de natureza material, organizacional e de formação, ainda sofre as de cunho epistemológico (que pesquisa é essa? Como se define, como se reconhece?) e até ideológico (será bom confundir o trabalho do professor e o do pesquisador?). Mas alguns argumentos poderosos se levantam para neutralizar esses obstáculos; o mais forte deles, a nosso ver, aponta a atividade de pesquisa e a formação para ela como importantes aliados do desenvolvimento profissional do professor. Erickson (1989) chega a afirmar que a prática de pesquisa é decisiva para ajudar o professor da educação básica a conquistar sua autonomia plena, a sair da situação de dependência, quase de imaturidade, em relação aos professores do ensino superior, na qual ainda se encontra.

A questão deve ser vista também pelo ângulo da própria pesquisa na área da educação, não apenas do seu pesquisador. É ela que está deixando a desejar, quanto ao que dela se espera e ao que se propõe, como toda pesquisa, em qualquer área: contribuir para a busca de soluções de problemas dessa área. A complexidade do fenômeno educacional, situado na confluência de várias disciplinas, cuja contribuição é imprescindivel para abarcar essa complexidade, e, ainda, a fragilidade desse fenômeno, que exige um tratamento metodológico adequado, têm provocado uma migração maciça dos estudos da área educacional para as abordagens qualitativas, nem sempre com o devido cuidado e muitas vezes com consequências indesejáveis (ANDRÉ; LÜDKE, 2004).

Em paralelo a essas dificuldades, parece haver um gap entre o professor e a pesquisa, que está prejudicando tanto um como a 
outra. Ou seja, o professor fica alijado de uma atividade indispensável para o seu desenvolvimento profissional e a pesquisa fica limitada ao alcance previsto dentro das condições, dos métodos, dos interesses e dos problemas determinados pela Universidade, deixando de se expandir para os temas, os objetivos, os problemas e, principalmente, os sujeitos que estão próximos desses problemas, os professores da educação básica. Há entre pesquisadores da educação iniciativas muito interessantes para tentar cobrir esse gap, procurando resgatar uma união fértil entre o trabalho do pesquisador da Academia, ou da Universidade, e o do professor da educação básica, exercendo também a atividade de pesquisador. São propostas de trabalho com a pesquisaação, tão bem defendida e praticada por Zeichner (2002), ou de pesquisa em grupos, como exemplificam Borba e Araújo (2004), ou ainda a pesquisa em colaboração, experimentada por Fiorentini (2004), só para indicar alguns exemplos recentes, entre as muitas iniciativas nessa direção. É importante atentar para esse tipo de esforço, que tenta cobrir o gap também pelo lado epistemológico, pois o próprio objeto de pesquisa tem tido o seu conhecimento limitado, prejudicado mesmo, pela falta de conjugação dos dois polos necessariamente envolvidos nele, o do professor da universidade e o do professor da educação básica. Ambos precisam combinar suas respectivas perspectivas para oferecer as melhores condições de construção do conhecimento sobre o fenômeno educacional, sempre nos limites da fragmentação que caracteriza todo conhecimento.

Com relação a essa questão, queremos registrar a entrada de um novo conceito, que pode ensejar interessantes e frutíferas análises, de modo especial sobre o aspecto epistemológico já mencionado. É o conceito de circularidade do conhecimento ou do saber, sugerido por J-L Martinand, um pesquisador francês, em entrevista a Burguière (2002). Juntamente com a pesquisadora Christiane Étévé, do Institut National de Recherche Pédagogique(INRP), e outros pesquisadores desse instituto, ele discute, em um número específico da revista editada pelo próprio INRP, Recherche et Formation (n. 40, 2002), essa ideia de circularidade, em confronto com alguns conceitos paralelos a ela. Observe-se que eles falam da circularidade do saber e não apenas de sua circulação, como é comum se ver quando se trata da transmissão ou da transferência de conhecimento. 
A ideia parece bastante oportuna para a nossa discussão, pois capta com perspicácia o movimento de comunicação entre os dois polos mencionados, o da Universidade e o da escola de educação básica, por meio do trabalho de pesquisa de seus professores, de ambos os polos, sem que fique patente superposição ou hierarquização entre eles. A ideia de circularidade indica bem essas idas e vindas, essa circulação entre as duas fontes produtoras de saber, cada uma enriquecendo a seu modo a construção do conhecimento a seu respeito. Superam-se assim, segundo seus autores, certas limitações percebidas nos conceitos de transferência, transmissão, tradução e mesmo transposição didática, que sempre implicam uma direção do movimento, de cima para baixo, do centro para a periferia, ou seja, da Universidade, produtora do conhecimento, para os professores da educação básica, seus aplicadores. Étévé (2001) apresenta uma boa introdução a essa questão, em artigo que discute a comunicação científica, frente às chamadas sciences du trasnfert (ciências da transferência). Com sua grande experiência de trabalho com os meios de comunicação de pesquisa desenvolvidos pelo INRP (órgão destinado à produção e à comunicação do conhecimento na área da educação), essa pesquisadora está muito bem situada para discutir com propriedade a questão da circulação e da circularidade desse conhecimento.

Os estudos sobre o saber docente, especialmente representados pelos de Tardif (2000; 2002) e Tardif, Lessard e Lahaye (1991), mas contando com a contribuição de vários outros autores, deram um grande impulso em direção ao reconhecimento do trabalho do professor e de seu produto, como parte do capital de conhecimento construído na área da educação. A proposta do conceito de circularidade do saber pode representar mais um passo naquela direção, ajudando-nos a perceber e a situar com maior clareza o papel da pesquisa desse professor, com uma função específica e insubstituível para a construção do conhecimento, além da importância há muito reconhecida para o seu desenvolvimento profissional. Estamos certos de que a discussão despertada ao redor desse conceito foi muito proveitosa para o nosso estudo.

Nosso novo estudo focaliza um importante meio de aproximação entre o professor e a pesquisa, nosso objeto de investigação há anos. Esse meio é representado pelo mestrado, como ficou claro no parágrafo 
já transcrito, que fecha o artigo para o Cadernos de Pesquisa $n^{\circ} 125$ (LÜDKE; CRUZ, 2005). A passagem pelo curso de mestrado vem sendo vista como o caminho mais viável, em termos realistas, para a formação de professores da educação básica como pesquisadores. Os cursos de graduação, de modo especial as licenciaturas, não têm conseguido desempenhar a contento esse papel formador. Continuamos a acreditar, não obstante, que a formação do futuro pesquisador se inicia, ou deve se iniciar, nos cursos de graduação, como, aliás, ocorre em vários cursos, especialmente nas áreas das ciências exatas. É nesses cursos que começam a serem estimulados e desenvolvidos os talentos dos jovens estudantes, que virão a florescer, mais tarde, nos cursos de mestrado e doutorado, no trabalho nos institutos de pesquisa e na própria Universidade.

O curso de mestrado, por sua vez, vai se tornando uma oportunidade de aperfeiçoamento para o professor, cada vez mais acessivel. Com mais de 90 programas espalhados em nosso País, ele já atinge cifras importantes em termos de qualificação do corpo docente de estados e municípios, tanto na rede pública quanto na particular. Também vai se alterando o quadro geral das carreiras docentes nos dois níveis de ensino. No nível superior, as oportunidades de trabalho para os jovens ingressantes vão se tornando mais difíceis, sobretudo com a redução do número de vagas para professores iniciantes nas universidades públicas. Igualmente, os salários desses professores já não são tão mais elevados em relação aos dos professores de algumas escolas de educação básica, de modo especial aos do ensino médio nas instituições particulares e das escolas federais ou colégios de aplicação. Os salários dos professores desse nível, mesmo os das escolas da rede pública, já começam a integrar um diferencial, referente à qualificação pelo título de mestre. Ao longo da carreira, esse diferencial vai se avolumando, devido ao acúmulo de anuênios e quinquênios, o que vai tornando essa carreira um pouco mais atraente, bem como propiciando condições para que profissionais mais qualificados permaneçam na educação básica.

Esses fatores vão se conjugando para resultar em um número crescente de professores que buscam o mestrado, por diferentes razões, é certo, mas também, entre elas, a procura de ajuda para enfrentar 
com mais segurança os problemas que vivem em suas escolas, com seus alunos. Quantos deles, após concluírem seu curso de mestrado, retornam para o trabalho na educação básica? Durante a proposição do nosso estudo, um rápido levantamento junto às últimas turmas formadas em nosso programa, na PUC-Rio, mostrou que quase metade dos concluintes se enquadrava nessa situação. Que sabemos deles, já de volta ao seu trabalho, após o mestrado, a não ser informações colhidas espontaneamente, em encontros casuais, em geral muito simpáticos e calorosos, porém, insuficientes para permitir uma visão do que representou o curso para eles e para o seu trabalho nas escolas? É isso que o nosso estudo pretendeu oferecer: informações colhidas junto aos formados nos cursos de mestrado que retornaram ao seu trabalho em instituições da educação básica (ou nunca o deixaram), no intuito de conhecer mais de perto, com os sujeitos que viveram recentemente o processo, como se deu essa formação, tanto em relação às suas expectativas pessoais quanto em função das exigências e necessidades do seu trabalho nas escolas.

Tem-se desenvolvido um esforço de análise da situação dos nossos cursos de pós-graduação, mestrado e doutorado, por iniciativa do Inep e da Anped, de modo especial (ANDRÉ, 2001a; BRZEZINSKI; GARRIDO, 2001; WARDE, 1993), em trabalhos de teses e dissertações (ROMANOWSKI, 2002; VENTORIM, 2005) e também em trabalhos publicados em periódicos, mais antigos ou mais recentes (WARDE, 1990; MARIN; BUENO; SAMPAIO, 2005). Mas esse esforço tem se concentrado, em geral, na análise de produtos desses programas, que são as dissertações e as teses, procurando, por meio deles, detectar os problemas por eles vividos. Não encontramos estudos que tenham focalizado os sujeitos que passaram, ou estão passando, por esses cursos para saber deles, diretamente, o que consideram mais proveitoso, tanto em termos de disciplinas cursadas como em função da preparação do trabalho de dissertação ou de tese. Dentro do programa de pesquisas do GEProf, em sua dissertação de mestrado, Portella (2008) realizou uma pesquisa que versa sobre a experiência do mestrado de professores de diferentes áreas de uma mesma escola pública, com interessantes constatações sobre as repercussões dessa experiência, quando se considera o conjunto de professores que dela se beneficiaram. 
O mestrado representa, praticamente, a primeira oportunidade concreta de realização de uma pesquisa de iniciativa do próprio professor-mestrando, contando, é claro, com os auxílios disponíveis no programa, como o conjunto de disciplinas oferecidas, as bolsas de estudo, cada vez mais curtas, mas ainda disponíveis, os recursos bibliográficos e de informática, as múltiplas atividades estimulantes que ocorrem dentro de uma universidade, o convívio assegurador dos colegas, que estão no mesmo barco, e, de modo particular, o apoio da orientação da dissertação, um dos melhores (e raros) exemplos de parceria desenvolvidos nas instituições de ensino superior, onde, em geral, domina um clima de competição, próprio da cultura de concorrência por postos na carreira e auxílios para pesquisa. Para nosso estudo, foi de grande interesse focalizar essa primeira (em geral) oportunidade de exercício da pesquisa por parte do professor da educação básica, no seu curso de mestrado. Como foi escolhido seu tema? Teve alguma relação direta com os problemas que vivia em sua escola? As disciplinas e a bibliografia estudada ajudaram a esclarecer esses problemas? Ou a passagem pelo mestrado representou um desvio, uma fuga desses problemas, em direção a outro tipo de atividade profissional, a outro nível de ensino, o superior talvez? As discussões, as ideias, os autores estudados, as teorias reveladas foram motivo para o aprofundamento de seu compromisso com o trabalho em sua escola ou, ao contrário, o despertaram para outros interesses, para outras direções?

Essas e várias outras questões levantadas para este estudo continuam nossa linha de investigação sobre as relações entre o professor da educação básica e a pesquisa. Com a vivência concreta da experiência do mestrado, com tempo e recursos à sua disposição, ainda que limitados, como esse professor se vê, após a volta ao seu trabalho habitual nas escolas, frente aos problemas que tão bem conhece? Nossas análises, e a de tantos estudiosos da questão, indicam a necessidade de aproximação entre as escolas da educação básica e a Universidade, se quisermos desenvolver uma pesquisa que responda aos problemas mais urgentes da nossa educação. O mestrado representa uma ponte já construída, há bastante tempo, entre esses dois pólos. Como anda o trânsito por essa ponte e a que destinos tem levado os profissionais que por ela passam? Se pensarmos como Nóvoa (2002), para quem uma formação continuada significativa para o professor deve levar em 
consideração sua vida, profissão e a instituição à qual se dedica, o que ele denomina trilogia da formação docente, como estaria o mestrado nesse contexto? Estaria ele contribuindo para essas três dimensões?

Um estudo sobre o curso de mestrado, tal como visto pelos seus diplomados, vem preencher uma lacuna no esforço de avaliação que vem sendo efetuado sobre os nossos programas de pós-graduação, sobretudo pela Capes. O sistema de avaliação que ela vem desenvolvendo há mais de 20 anos é considerado muito refinado e tem sido procurado como modelo por vários países da América Latina. Entretanto, ele não inclui a participação de pós-graduandos, nem de pós-graduados ou de seus formadores, justamente os sujeitos mais envolvidos em seus problemas e mais interessados em suas soluções. Nosso estudo poderá fornecer importante contribuição exatamente sobre esse aspecto central, ainda ausente do modelo Capes. Nossas universidades poderão se beneficiar desse material para estudar possivveis melhorias de seus programas de pós-graduação. Nossas escolas, e o próprio sistema de ensino fundamental, também poderão, a partir das informações obtidas, tomar medidas que favoreçam o desenvolvimento profissional de seus professores, pelo mestrado, e igualmente assegurem a busca de soluções para seus problemas.

\section{Principais resultados do estudo}

A interação com 30 professores por meio de entrevistas foi muito proveitosa, oferecendo um rico conjunto de constatações, das quais destacaremos algumas das mais importantes.

A composição do grupo de entrevistados revela uma variedade quanto à formação no ensino de nível médio: 18 deles no antigo curso normal; os outros, em cursos técnicos. No nível superior, 17 cursaram licenciatura em Pedagogia, os demais fizeram outros cursos de licenciatura. São professores com experiência de magistério, distribuídos pelos diferentes segmentos da educação básica. Quase todos afirmaram não terem tido contato direto com a prática de pesquisa, seja no curso de graduação, seja no exercício do trabalho docente. Constituem exceção os dois entrevistados que tiveram oportunidade de se beneficiar de uma 
bolsa de iniciação científica e da experiência por ela proporcionada de participação em um grupo de pesquisa.

É oportuno ressaltar aqui a possibilidade de iniciação à pesquisa representada pelos trabalhos de final de curso ou monografias, exigidos na maioria dos nossos cursos de graduação. Eles poderiam oferecer ao estudante uma série de atividades próprias de introdução à pesquisa, preparando-o para futuros desenvolvimentos em cursos de mestrado e doutorado, ou no próprio exercício do magistério, se possível em colaboração com pesquisadores da Universidade. Essa oportunidade é, em geral, mal aproveitada em nossos cursos de graduação, talvez por falta de um entendimento claro de como esse trabalho poderia ser conduzido, sem esperar que leve a uma formação completa do estudante como futuro pesquisador, mas sem desperdiçar o que se pode oferecer para a sua familiarização com várias habilidades exigidas pelo trabalho de pesquisa.

De modo geral, nossos entrevistados se ressentem da falta dessa preparação para a pesquisa em seus cursos de graduação e se declaram chegando ao mestrado com uma noção muito pouco precisa do que seja pesquisa na realidade. Boa parte deles, 22, fez algum curso de especialização de curta duração, mas, no conjunto, reclamava, ao entrar no curso de mestrado, da oferta de cursos de fundamentação teórica e de preparação metodológica. Após concluírem o curso e defenderem suas dissertações, como nos declararam, acabam reconhecendo que, a despeito da oferta desses cursos, grande parte da carga de trabalho para a fundamentação teórica e metodológica de suas pesquisas recaiu sobre os ombros de seus orientadores.

Um segundo grupo de informações importantes para nosso estudo se refere à análise de diferentes aspectos do curso de mestrado realizado pelos entrevistados. Queríamos saber como eles o viram e sentiram, desde o processo de seleção para a entrada no curso até as disciplinas oferecidas e cursadas, a proposição do projeto de pesquisa e seu desenvolvimento até a defesa da dissertação. A grande procura pelo curso, em uma universidade pública bastante prestigiada, com limites de vagas disponiveis, distribuídas pelas várias linhas de pesquisa do programa, já representava desafio para nossos entrevistados, 
enquanto candidatos na grande competição. Dentro desse clima, é natural a procura de estratégias para ajudar a atingir o objetivo, tais como a aproximação de um grupo de pesquisa do programa, a frequência como aluno especial de alguma de suas disciplinas ou o estudo mais aprofundado de temas de interesse reconhecido de alguns de seus professores. Assim, a familiaridade com a literatura, ou mesmo com os participantes do programa, pode representar fator facilitador para a entrada de nossos entrevistados no curso. Conforme alguns depoentes destacaram: "Tentei, não passei. Comecei a frequentar o grupo do professor B, ai foi mais fácil, porque estava por dentro da literatura (Elisa)". "Na falta de uma bibliografia específica para a prova escrita, buscava-se uma solução: recolhia textos nas pastas dos professores e de outros alunos do mestrado (Daniel)."

Uma vez dentro do curso, foi preciso enfrentar uma série de dificuldades para levá-lo a bom termo. Muito poucos (apenas quatro) obtiveram o benefício de uma bolsa de estudos. Como todos trabalhavam em suas escolas, foi necessário um grande esforço para frequentarem as aulas, deslocando-se alguns de localidades bem distantes, sem a esperada atenção da secretaria de educação para a dispensa, pelo menos, de parte da carga horária do magistério. Assim, alguns dos entrevistados tiveram que sacrificar parte das atividades previstas pelo curso, como a participação em grupos de pesquisa. Felizmente, isso ocorreu apenas em poucos casos e a maioria se beneficiou dessa importante atividade, considerada por todos como muito efetiva. As disciplinas cursadas foram também muito valorizadas aos olhos dos entrevistados, de modo especial, aquelas que se aproximavam mais de seus temas de pesquisa, mas mesmo as outras foram consideradas muito válidas, como oportunidades de aprendizagem, ao lado de outros componentes do curso, contribuindo para a ampliação da visão dos mestrandos sobre a educação, afirmaram.

Um item focalizado com especial interesse em nossa pesquisa foi o que reúne a proposição do problema a ser estudado, seu desenvolvimento em forma de projeto, a realização dos trabalhos decorrentes, o acompanhamento pelo processo de orientação e, finalmente, a defesa da dissertação. Quase todos os entrevistados relembraram a dificuldade enfrentada para apresentar o pré-projeto 
de pesquisa, exigência do processo de seleção. Como não tinham noção precisa de pesquisa, expressão usada por eles, sentiam-se muito inseguros para fazê-lo e se apegaram às estratégias já mencionadas para aproximação do programa. Os poucos que haviam tido bolsa de iniciação científica na graduação sentiram-se um pouco mais à vontade, como disseram. Os que tiveram chance de participar de grupo de pesquisa antes de ingressar no mestrado destacaram a relevância dessa experiência. A professora Marcela relata: "Sim, participei. Isso foi um diferencial na minha formação. Depois eu fiz mestrado com a professora com a qual eu trabalhava no grupo". O professor Lúcio afirma: "Acho muito importante a iniciação científica, ela te apresenta o lado positivo e o negativo do universo da pesquisa."

Dos muitos que não tiveram a chance de participar da iniciação científica, chamou-nos atenção o que disse Karina:

\footnotetext{
Quando apareceu a oportunidade de fazer a prova de seleção para o Mestrado eu não tinha a dimensão ainda do que era o mestrado, do que era uma pesquisa de mestrado. Sempre tive muita curiosidade em relação a como fazer coisas, não necessariamente a pesquisa, até porque não tive contato na graduação. Não houve grandes problemas para mim, pois tenho facilidade para escrever, mas acho que "é um processo muito cruel" justamente porque as pessoas não têm oportunidade de ter contato antes com toda essa estrutura acadêmica de como fazer pesquisa.
}

À medida que foram sendo desenvolvidas as disciplinas, também foi crescendo a familiarização com a discussão teórica corrente na educação e com o vocabulário próprio da pesquisa, do qual quase todos os informantes se declararam distantes antes da entrada no mestrado, mesmo os que já se consideravam com alguma desenvoltura e domínio em relação à escrita: "não a acadêmica, entretanto", ressalvam.

A participação em grupos de pesquisa foi considerada essencial pelos 23 mestrandos que puderam dela se beneficiar. A orientação da dissertação foi avaliada como muito positiva, salvo em dois casos, nos quais ocorreram problemas bastante específicos. Para o conjunto dos entrevistados, ela representou ocasião de apoio, de troca, de negociação, de desenvolvimento da autonomia. O professor orientador sempre esteve disposto a ajudar, a apoiar suas ideias, trocando com 
eles informações entre o pesquisador experiente e os iniciantes, por meio de uma negociação em busca da abordagem mais viável para o estudo do problema que traziam. Vários mestrandos tiveram trabalhos apresentados em encontros científicos e mesmo publicados em periódicos da área, graças a essa efetiva interação com seus orientadores, da qual resultavam trabalhos efetuados em colaboração, como o próprio programa estimulava.

O trajeto que vai do pré-projeto até a defesa da dissertação pode ser visto como o eixo central que sustenta o processo de mudança em direção ao desenvolvimento do pesquisador, tal como visto e relatado pelos nossos entrevistados. Seus componentes, como discutimos brevemente, vão encaminhando o mestrando nessa direção, até chegar à defesa da dissertação, ocasião ainda de aprendizagem, a partir das observações dos membros da banca, que examinaram o trabalho, assim como já tinha feito o professor convidado para o exame de qualificação do projeto. A análise desse trajeto, a partir das informações dos mestres entrevistados, nos confirmou a função central desse eixo, expressa em muitas de suas afirmações, tais como: "aprendi pesquisa no mestrado", "foi no mestrado que aprendi a trabalhar com metodologia quantitativa e qualitativa”, "o mestrado me trouxe maturidade teórica”, "o mestrado me trouxe estrutura de pesquisa". Foram muitas as afirmações sobre a aprendizagem da linguagem acadêmica, assegurada pela passagem pelo curso.

\section{Concluindo}

As razões que levaram professores da educação básica a procurarem o curso de mestrado foram variadas, como revelaram nossos entrevistados; desde problemas de natureza prática, de suas escolas, até questões teóricas, políticas e também relativas às suas próprias carreiras e ao desenvolvimento profissional. Procuramos saber deles, uma vez de volta ao seu trabalho nas escolas, como viam então o que representou o mestrado. Nossa análise sobre suas manifestações trouxe uma das revelações mais interessantes do estudo. O movimento de ida em direção ao mestrado foi, de certa forma, superado pelo de volta às escolas. De modo especial, ao se considerar o problema levado pelo 
professor, na esperança de encontrar uma solução pela via da pesquisa no mestrado, as reflexões do já mestre mostram uma importante evolução, não exatamente na direção prevista, mas talvez atingindo um alvo bem mais amplo.

Segundo expressaram praticamente todos os entrevistados, houve uma transformação no tratamento do seu problema de pesquisa, por meio do encaminhamento no curso. Ao longo do trajeto em que foram entrando as disciplinas cursadas, as discussões nos grupos de pesquisa e, sobretudo, a interação com o professor orientador, a perspectiva de pesquisa foi se consolidando, tornando-se mais clara e se distanciando do modo de entender o que é a pesquisa que traziam, como reiteraram os entrevistados. "Eu não sabia bem o que era pesquisa, o mestrado me ensinou", disseram vários. E o exame de suas dissertações, que pudemos efetuar, confirmou, de modo geral, a informação prestada por eles sobre a aproximação do tema original, que haviam trazido ao entrar no programa, ainda que o trabalho não tivesse resolvido o problema, tal como esperavam um tanto ingenuamente ao chegarem.

De volta à escola, todos se declararam enriquecidos com a experiência vivida no mestrado, mesmo reconhecendo não ter conseguido chegar à solução do problema que propuseram para o estudo. Alguns até consideram que se aproximaram bastante dela, já que haviam caminhado um tanto antes de chegar ao mestrado, pela própria reflexão e experiência, pela participação em grupos de pesquisa e bolsas de iniciação científica, como já vimos. Perguntados sobre sua percepção como pesquisador autônomo, já suficientemente desenvolvido para levar adiante uma pesquisa sob sua coordenação, convidando colegas da escola para formar um grupo, poucos responderam afirmativamente. A maior parte reconhece que seu desenvolvimento foi grande, mas não o bastante para conferir a segurança de assumir a coordenação de uma pesquisa, preferindo confiar essa função ainda a um professor mais experiente, da Universidade. Todos, porém, afirmaram enfaticamente, por meio de expressões bastante aproximadas, que o mestrado ampliou sua visão: "agora eu olho meus alunos e os problemas da minha escola com outros olhos". Isso nos fez refletir sobre a grande mudança ocorrida nesses professores pela influência do curso de mestrado. Se eles conseguem ver a realidade na qual trabalham sob um prisma diferente, 
o da pesquisa, a sua disposição e perspectiva para esse trabalho tomam outra direção, com reflexos positivos para sua atuação como professor e para resultados que vierem a ser alcançados possivelmente pelo esforço da pesquisa, para o qual vários se declararam prontos para alçar vôo.

Com o surgimento de mestrados profissionais ligados à educação, parece haver, em alguns casos, uma tendência a considerar esse tipo de mestrado mais adequado ou mais interessante para o professor. Ressaltamos que nossos entrevistados cursaram o mestrado acadêmico, com possibilidade de prosseguir para um doutorado, se desejarem, e, como destacamos, tirando grande proveito do curso realizado. Nossa investigação não confirma a ideia de que o mestrado acadêmico está distante da realidade do professor ou, ainda, que ele pouco aproveita desse curso para seu trabalho na educação básica. A nosso ver, cabe uma interrogação, que pode servir como pista para outros estudos: encerrar ou priorizar a participação de professores da educação básica em mestrados profissionais não seria, mais uma vez, aumentar a distância entre teoria e prática (como ainda se faz na graduação, separando licenciatura e bacharelado), colocando os professores, novamente, em um lugar "menor" ou menos valorizado, que cabe ao ensino, em contraposição à pesquisa?

Nosso estudo também foi oportuno para mostrar que a parceria entre Universidade e educação básica, pela via do mestrado de professores, propiciou a discussão de temáticas que interessam a ambas. Constatamos que os professores mestrandos conseguiram conciliar seus temas de interesse com os interesses do programa e dos orientadores. Embora não tenham saído, como reconhecem, com a solução pronta para o seu problema de pesquisa, puderam discutir suas questões de modo satisfatório e enriquecedor, como se espera que aconteça na prática de pesquisa.

Outro aspecto importante a ser ressaltado para a consideração de políticas públicas em educação é a atenção ao estímulo para o desenvolvimento profissional dos professores da educação básica, pela frequência ao curso de mestrado. Para isso, eles deveriam contar com alguma ajuda financeira, por meio de bolsas e também pela dispensa de pelo menos parte de sua carga horária junto a suas 
escolas. Assim procedendo, estaremos caminhando na direção de uma aproximação entre a teoria, tão importante e tão valorizada pelos nossos entrevistados, assegurada pelo trabalho da Universidade no curso de mestrado, e a prática, desenvolvida pelo professor mestrando, oferecendo a visão da realidade escolar, indispensável à boa formação de todos os professores.

A interrogação inicial, que deu origem a este estudo, sobre a validade do curso de mestrado como iniciação de professores da educação básica na prática de pesquisa encontrou resposta plenamente positiva. A interação com 30 professores, que compartilharam conosco sua experiência recente nesse curso, mostrou a importância decisiva que ele teve para sua formação como pesquisadores e seu trabalho como professores. Mostrou também a urgência de se efetuarem estudos sobre aspectos específicos de programas de mestrado, como o que generosamente se abriu ao nosso estudo, para conhecer de perto suas necessidades, seus recursos e problemas, e oferecer sugestões para sua maior efetividade. Esses estudos, ao analisar o processo pelo qual se desenvolvem os programas, teriam um alcance bem mais amplo do que os que focalizam apenas seus produtos.

Recebido em 30/8/2010

Aprovado em 08/5/2011

\section{Referências bibliográficas}

ANDERSON, G. L.; HERR, K. The new paradigm wars: Is there room for rigorous practitioner knowledge in schools and universities? Educational Researcher, v. 28, n. 5, p.12-21, 1999.

ANDRÉ, M. Estado da Arte da formação de professores no Brasil. Educação e Sociedade, v. 110, n. 68, p. 301-309, dez. 2001.

ANDRÉ, M.; LÜDKE, M. Conquistas e problemas atuais em metodologia de pesquisa na área de formação de professores. In: REUNIÃO ANUAL DA ANPED, 27., 2004, Caxambu. 
BORBA, M. C.; ARAÚJO, J. L. (Orgs.). Construindo pesquisas coletivamente. In: _-_-_-_. Pesquisa qualitativa em educação matemática. Belo Horizonte: Autêntica, 2004.

BORGES, C. M. F. O professor da educação básica de $5^{\mathrm{a}}$ a $8^{\mathrm{a}}$ série e seus saberes profissionais. 2002. Tese (Doutorado em Educação) Departamento de Educação, Pontifícia Universidade Católica do Rio de Janeiro, Rio de Janeiro.

O professor da educação básica e seus saberes profissionais. Araraquara: JM Editora, 2004.

BRZEZINSKI, I.; GARRIDO, E. Análise dos trabalhos do GT de formação de professores: o que revelam as pesquisas do período 1992-1998. Revista Brasileira de Educação, n. 18, p. 82-100, set./dez. 2001.

BURGUIĖRE, E. Entretien avec Jean-Louis Martinand. Recherche et Formation, n. 40, p. 87-94, 2002.

CARVALHO, M. S. A pesquisa educacional sobre a escola pública de ensino fundamental, nos projetos e relatórios de pesquisa elaborados por docentes de universidades brasileiras. 2004. Tese (Doutorado em Educação) - Departamento de Educação, Universidade Federal do Rio de Janeiro, Rio de Janeiro.

COCHRAN-SMITH, M.; LYTLE, S. L. The teacher research movement: a decade later. Educational Researcher, v. 28, n. 7, p.15-25, 1999.

CONTRERAS, J. D. La autonomía del profesorado. Madri: Morata, 1997.

DURAND, M.; SAURY, J.; VEYRUNES, P. Relações fecundas entre pesquisa e formação docente: elementos para um programa. Cadernos de Pesquisa, v. 35, n. 125, p. 37-62, maio/ago. 2005.

ERICKSON, F. Métodos Cualitativos de Investigación sobre la Enseñanza. In: WITTROCK, M. C. La investigación de la enseñanza, II - métodos cualitativos y de observación. Barcelona: Paidós Educador, MEC, 1989. 
ÉTÉVÉ, C. De la communication scientifique aux “sciences du transfer”. Revue Française de Pédagogie, n. 135, p.69-81, abr/jun. 2001.

FIORENTINI, D. Pesquisar práticas colaborativas ou pesquisar colaborativamente? In: BORBA, M. C.; ARAÚJO, J. L. (Orgs.). Pesquisa qualitativa em educação matemática. Belo Horizonte: Autêntica, 2004.

HAMMERSLEY, H. A. On the teacher as researcher. In: HAMMERSLEY, M. (Org.). Educational Research - Current Issues. Londres: The Open University, 1993.

HUBERMAN, M. O ciclo de vida profissional dos professores. In: NÓVOA, A. (Org.). Vidas de professores. Porto: Porto Edit, 1992.

LÜDKE, M. Investigando sobre o professor e a pesquisa. In: ROMANOWSKI, J. P.; LÜDKE, M. Sobre a socialização profissional de professores. Cadernos de Pesquisas, n. 99, p. 5-15, nov. 1996.

A complexa relação entre o professor e a pesquisa. In: ANDRÉ, M. (Org.). O papel da pesquisa na formação e na prática dos professores. Campinas: Papirus, 2001a.

(Coord.). O professor e a pesquisa. Campinas: Papirus, 2001b.

(Coord.). A pesquisa e o professor da educação básica na visão de professores da universidade. Relatório de pesquisa. Departamento de Educação, PUC-Rio, 2002.

LÜDKE, M. Investigando sobre o professor e a pesquisa. In: ROMANOWSKI, J. et al. (Orgs.). Conhecimento local e conhecimento universal: pesquisa, didática e ação docente. Curitiba: Champagnat, 2004.

. (Coord.). O que conta como pesquisa. São Paulo: Cortez, 2009.

LÜDKE, M.; CRUZ, G. B. Aproximando universidade e escola de educação básica pela pesquisa. Cadernos de Pesquisa, v. 35, n. 125, p. 81-109, maio/ago. 2005. 
MARIN, A. J.; BUENO, J. G. S.; SAMPAIO, M. M. F. Escola como objeto de estudo nos trabalhos acadêmicos: 1981-1998. Cadernos de Pesquisa, v. 35, n. 124, p. 171- 199, jan./abr. 2005.

NóVOA, A. Formação de Professores e Trabalho Pedagógico. Lisboa: Educa, 2002.

PORTELLA, V. C. M. Professores-mestres: a contribuição do mestrado na formação continuada de professores da educação básica. 2008. Dissertação (Mestrado em Educação) - Departamento de Educação, Pontifícia Universidade Católica do Rio de Janeiro, Rio de Janeiro. 136 p.

ROMANOWSKI, J. P. As licenciaturas no Brasil: um balanço das teses e dissertações dos anos 90. 2002. Tese (Doutorado em Educação) Departamento de Educação, Universidade de São Paulo, São Paulo.

SANTOS, L. C. P. Dilemas e Perspectivas na Relação entre Ensino e Pesquisa. In: ANDRÉ, M. (Org.). O papel da pesquisa na formação e na prática dos professores. Campinas: Papirus, 2001.

SCHÖN, D. The reflective pratitioner. Londres: Temple Smith, 1983.

TARDIF, M. Saberes profissionais de professores e conhecimentos universitários. Revista Brasileira de Educação, n. 13, p. 5-24, jan./abr. 2000 .

Saberes docentes e formação profissional. Petrópolis, RJ: Vozes, 2002.

TARDIF, M.; LESSARD, C.; LAHAYE, L. Os professores face ao saber: Esboço de uma problemática do saber docente. Teoria \& Educação, Porto Alegre: Panônica, n. 4, p. 215-233, 1991.

TARDIF, M.; ZOURHLAL, A. Difusão da pesquisa educacional entre profissionais do ensino e círculos acadêmicos. Cadernos de Pesquisa, v. 35, n. 125, p. 13-35, maio/ago. 2005. 
VENTORIM, S. A formação do professor pesquisador na produção científica dos Encontros Nacionais de Didática e Prática de Ensino: 1994-2000. 2005. Tese (Doutorado em Educação) - Departamento de Educação, Universidade Federal de Minas Gerais, Belo Horizonte.

WARDE, M. J. O papel da pesquisa na pós-graduação em educação. Cadernos de Pesquisa, n. 73, p. 67-75, maio 1990.

A produção discente dos programas de pós-graduação em educação no Brasil (1982-1991). In: ANPED. Avaliação e perspectivas na área da educação. Porto Alegre: Anped, 1993.

ZEICHNER, K. M. A pesquisa-ação e a formação docente voltada para a justiça social: Um estudo de caso nos Estados da Unidos. In: PEREIRA, J. E. D.; ZEICHNER, K. M. (Org.). A pesquisa na formação e no trabalho docente. Belo Horizonte: Autêntica, 2002. 